\title{
Unhomeliness in Jhumpa Lahiri's "Hema and Kaushik"
}

\author{
By Sayyed Rahim Moosavinia* \\ Somaye Sharify
}

Frank writes that the characters of migration literature invariably deal with migration in different ways, from "the experience of migration and the uncertainty of displaced identities as destructive, agonizing, and painful to the experience of migration and displacement as productive, fascinating, and appealing, but in general, as he argues, the migration literature concerns redefining immigrants" identities to show their heterogeneous or hybrid feature. Jhumpa Lahiri has treated the same themes of migration and postcoloniality in most of her works. Being an American of Indian, or more accurately Bengali, descent, her works all have echoes of her life. This essay focuses on the various ways in which Jhumpa Lahiri employs hybridity in the second part of Unaccustomed Earth, entitled "Hema and Kaushik", to convey the unhomeliness of her postcolonial subject. Briefly, it is an account of an ethnic-American man, Kaushik, who is unable to root himself, either emotionally or physically. In this sense, his story becomes an excellent example of a hybrid text since the author addresses the protagonist's unhomeliness by constructing a text that defies fixedness and shows the impossibility of clinging to a center. This study intends to argue that "Hema and Kaushik" is a narrative permeated by unhomeliness, both in the tales it tells and in the form that the narrative takes. By drawing on Bhabha's unhomeliness as a theoretical basis, this study intends to show that Jhumpa Lahiri breaks down the stabilized notions of home, homeland and national belonging thus depicting a more cosmopolitan picture of contemporary Indian diasporic community.

Keywords: Homeland, Hybridity, Identity, Jhumpa Lahiri, Unhomeliness

\section{Introduction}

Migration has recently turned into a buzzword thanks to the media's full coverage of immigrants crossing the borders, often under inhumane conditions, to reach the promised lands. It is almost impossible to watch or read news these days without any headlines on this topic. Some host nations view this international phenomenon as a threat to the homogeneity of their national identities and are looking for some preventative measures to take against its further growth. The political discussion of migration is beyond both the scope of this essay and the specialty of its writers. What this study intends to suggest is that dislocation or in Bhabha's term "unhomeliness" has become a norm, rather than the exception, to the point where it has given birth to a new literary genre called migration literature. According to Frank (quoted in Moslund 2010: 3), migration literature engages with "human identity, cultural identity, national identity and globalization processes". The characters of migration literature, he goes on to argue, invariably deal with migration in different ways, from "the experience of migration and the uncertainty of displaced identities as destructive, agonizing, and painful to the experience of migration and displacement as productive, fascinating, and appealing", but in general, as Frank maintains, migration literature concerns

\footnotetext{
*Associate Professor, Shahid Chamran University of Ahvaz, Iran.

${ }^{*}$ MA Graduate, Shahid Chamran University of Ahvaz, Iran.
} 
redefining immigrants' identities to show their impure and heterogeneous feature, as Moslund quoted (2010: 3).

Jhumpa Lahiri has treated the same themes of migration and postcoloniality in most of her works. Being an American of Indian, or more accurately Bengali, descent, her works all have echoes of her life. In an interview, Lahiri admits that although she spent her entire life in the West, she could not help feeling Indian due to her parents' presence in her life (Alfonso-Forero 2011: 134). In her debut collection of short stories, The Interpreter of Maladies (1999), she introduces us to some immigrant Bengali couples who try to straddle cultural borders with varying degrees of success: while the couple in the final story, "The Third and Final Continent" manages to negotiate hybrid identities, in "Mrs. Sen" the eponymous heroine fails to do so. In The Lowland (2013), Subhash demonstrates a sort of equilibrium vis-à-vis the concept of assimilation. A character like Subhash is always in between two cultural poles, embracing some norms of the alien culture and rejecting some others. As a result, he has been addressed as the more moderate immigrant in terms of assimilation. On the other hand, Gauri, as another major character of the same novel, is depicted as a more extreme instance of assimilation to the alien culture. Her case could be referred to as an instance of over-assimilation in Lahiri's oeuvre. Unaccustomed Earth (2008) is Lahiri's first work that focuses on the intercultural dilemma of second-generation immigrants. This work is divided into two parts. Whereas the first part consists of five individual stories, the second has a separate title, "Hema and Kaushik" and a different structure: the three stories are sequels.

This study will focus on the various ways in which Jhumpa Lahiri employs hybridity in the second part of Unaccustomed Earth, entitled "Hema and Kaushik", to convey the unhomeliness of her postcolonial subject (Lahiri 2008: 221-333). It intends to argue that "Hema and Kaushik" is a narrative permeated by unhomeliness, both in the tales it tells and in the form that the narrative takes. Briefly, it is the account of an ethnic-American man, Kaushik, who is unable to root himself, either emotionally or physically. In this sense, his story becomes an excellent example of a hybrid text since the author addresses the protagonist's unhomeliness by constructing a text that defies fixedness and shows the impossibility of clinging to a center.

\section{Methodology}

\section{Framing Unhomeliness}

The concept of hybridity is central to Bhabha's work in challenging notions of identity, culture, home, and homeland as coherent and unified entities that exhibit a linear historical development (Habib 2005: 750). Hybridity, for Bhabha, expresses a "state of unhomeliness," which he (1994) defines as "an extraterritorial and cross cultural initiations in which the borders between private and public, past and present, the psyche and the social develop an interstitial intimacy which questions binary divisions through which such spheres of social experience 
are often spatially opposed" (p. 9). Furthermore, he reminds us that to be unhomed is not to be homeless, "nor can the unhomely be easily accommodated in that familiar division of social life into private and public spheres" (Bhabha 1994: 9). But:

The unhomely moment creeps up on you stealthily as your own shadow and suddenly you find yourself with Henry James's Isabel Archer, in The Portrait of a Lady, taking the measure of your dwelling in a state of "incredulous terror". And it is at this point that the world first shrinks for Isabel and then expands enormously. As she struggles to survive the fathomless waters, the rushing torrents, James introduces us to the "unhomeliness" inherent in that rite of extra-territorial and cross-cultural initiation (Bhabha 1994: 9).

Drawing on Bhabha's unhomeliness as a theoretical framework, this study seeks to examine both the form and content of Jhumpa Lahiri's "Hema and Kaushik". The first part focuses on the form of the narrative. It intends to argue that "Hema and Kaushik" is a hybrid text par excellence since the author addresses the protagonist's unhomeliness by constructing a text that defies fixedness and shows the impossibility of clinging to a center. In this story, as this essay will show, textual unhomeliness is evident in the structure of the narrative itself as it is divided into three parts, as well as the combination of different narrative personae, settings and the employment of flashbacks in place of linear time.

The second part uses Bhabha's unhomeliness as a theoretical basis to question the classic view of home and homeland. It also seeks to challenge the simplistic notion of diasporic subject that can negotiate multiple identities only from the vantage point of his mother homeland. Rather, it will argue that unhomeliness destabilizes the notion of fixed boundaries thus, as Bhabha puts it, opens "ways of living at home abroad or abroad at home" (quoted in Huddart 2006: 53). By focusing primarily on the unhomely nature of Kaushik's diasporic experience, this essay will show that "Hema and Kaushik" breaks down the stabilized notions of home, homeland and national belonging, thus depicting a more cosmopolitan picture of contemporary Indian diasporic community.

\section{Unhomeliness in the Form of the Narrative}

It seems that the choice of the title of the stories is deliberately concerned with the theme of homeliness and unhomeliness. Postcolonial subjects constantly move from one to the other until they arrive or fail to arrive at a compromise. This movement is materialized in different ways for different characters. For Hema, it is a movement from home to the unhomely and back to a compromised stability. As for Kaushik, it seems that he could not digest hybridity or compromise. $\mathrm{He}$ endeavors to assimilate to the Americans, but in vain. Of course, other important elements in the life of these two characters determine the outcome of their behavior, such as family upbringing, their place at home (Calcutta for Hema and Bombay for Kaushik) and the temperament of their parents (especially the mother as they are very vital in fostering children's aspirations). More often 
than not, the particular interest of a character is indicative of his or her tendency, e.g. photography and travel for Kaushik and history and tradition for Hema.

Unhomeliness is made clear in the narrative as Lahiri resorts to postmodern modes and techniques in order to reveal the split in her postmodern postcolonial subject. In this work, unhomeliness is first and foremost evident in the structure of the narrative as it is divided in three short stories: "Once in a Lifetime", "Year's End" and "Going Ashore". Each is narrated through flashbacks and remembering. It is through these disconnected narratives that we get glimpses of Kaushik's life: his parents, his stepmother and his lovers. Kaushik's story thus becomes a succession of disconnected sequences, which focuses on Kaushik's fractured self. The unhomeliness is also evident in the use of different narrative personae. In "Once in a Lifetime" Hema is the focalizer, while in "Year's End" it is Kaushik; and in "Going Ashore" the focal point switches between the two protagonists. The unhomeliness is made clear in the changes of the physical settings, as well: "Hema and Kaushik" moves across multiple geographical locations, including India, the US, Italy, Palestine and Thailand. By "depicting an ongoing and inconclusive suspension between several locales", "Hema and Kaushik" shows how unhomeliness sometimes facilitates the negotiation of hybrid identities for some postcolonial subjects, as in the case of Kaushik, whose fluid identity enables him to easily connect to people across the globe (Fadda-Conrey 2009: 170).

\section{Content Analysis: Mother Homeland or Mother Diaspora}

Banerjee (2010) argues that for Lahiri's second-generation immigrants, the notion of home/homeland remains an imaginary place that they can never access in memory; consequently they often seek rootedness through their family, particularly through their mother figure. In "Hema and Kaushik", however, Lahiri chooses to put an end to the life of the mother, while letting her male counterpart live long enough to adapt to his new soil. It seems that Lahiri uses the mother figure as a metaphor for "Mother Homeland" in order to convey the unhomeliness of her second-generation-immigrant characters. As Munos (2013) discloses, while Lahiri's first generation immigrants are often haunted by the loss of their Mother India, their American-born offsprings are haunted by the loss of their Mother Diaspora. For Kaushik, however, the displacement is doubled because he is plucked from both his physical and emotional roots simultaneously. In this sense, Kaushik represents a typical postcolonial postmodern subject whose disorientation comes precisely from the destabilization of the centers that should contain him: family, home/homeland, and women. What follows is an attempt to show how these centers are gradually destabilized by the protagonist.

\section{Once in a Lifetime}

Unlike other second-generation-immigrant characters in Lahiri's works, whose in-betweenness remains psychological and emotional, Kaushik literally 
oscillates between his American and Indian identities by travelling back and forth between the US and India. The narrator in "Once in a Lifetime" tells us that Kaushik is born in Cambridge; that his parents were among the seasoned immigrants who left India in 1962, before the laws welcoming foreign students changed. However, by the time Kaushik turns nine, his father is offered a good position in Bombay so they decide to leave the US. Seven years later, however, Kaushik's father calls his immigrant friends to say that they are returning to Massachusetts for he has a new job there. He asks the narrator's parents if they could stay at their place until he finds a proper house for his family. When Kaushik returns to the United States, the host's daughter, Hema, is bewildered by his identity: "I did not know what to make of you" (Lahiri 2008: 240). Because Kaushik has lived in India, she associates him more with her parents than with herself. But she could not help noticing that he is not like her cousins in Calcutta, "who seemed so innocent and obedient when I visited them, asking questions about my life in America as if it were the moon, astonished by every detail. You were not curious about me in the least" (p. 240). She also observes that Kaushik consistently speaks English even when someone addresses him in Indian: "a faint accent present in your English, but not the strong accent our parents shared" (p. 232). Kaushik's father once proudly remarks that "even in Bombay we managed to raise a typical American teenager" (p. 238).

As the narrative progresses, Hema notices that Kaushik is in the house as little time as possible, going for a walk in the cold weather through the woods and along the streets where he is the only pedestrian. She spots him once while she is on the school bus, "shocked at how far you'd gone" (Lahiri 2008: 243). Hema accompanies him on one of these excursions where he begins to uncover the tombstones of a family. It is at this death spot that Kaushik eventually tells Hema the reason for their return to the US: that his mother is dying from breast cancer.

\section{Year's End}

Kaushik is the epitome of what Bhabha calls an unhomely subject, not only because he is cut across two home/homelands, but also because he is stuck in between the past and the present while displaced in both and belonging in neither. In "Year's End", we learn that his mother is already dead and his father has been to India to marry an Indian widow. Throughout this story, the reader notices a contrast between Kaushik's and his father's attitudes towards their present, which is shown not only by their adjustment to the host nation but also their reactions to the past. While the father seeks to put his traumatic past behind and negotiate a space for himself in his new homeland, Kaushik is unable to come to terms with either his past or present. Instead, he chooses to run away from both.

When we meet Kaushik in "Year's End", he is a college student and is going home to spend the Christmas vacation with his father's new family, including his stepmother and two stepsisters. On his way, he tries to imagine his father's new household because as far as he could remember, after his mother's death, his father decides to get rid of everything that reminds him of her. First, he removes 
all her photographs from the frames and albums and puts them in a shoebox. He also gives away her clothes, bags, cosmetics and colognes. He even disposes of his old car simply because his wife sat in it many times. Kaushik also observes that his father has given up lots of his old habits since his mother's death: he no longer drinks his late wife's favorite liquor and has stopped writing poetry. Yet, perhaps his new marriage is the best indicator of Kaushik's father's sign of adjustment. The fact that he chooses to marry an Indian woman and to bring her to the United States signifies this diasporic subject's willingness to negotiate an inbetween space for himself: i.e. an Indian home in an American homeland.

Unlike his father, Kaushik is unable to adjust himself to the present. In other words, the situation of in-betweenness seems too confusing for this dislocated subject to bear. That is why, as this study will show, he chooses to remain psycho-physically unhomely. In "Year's End", we learn that Kaushik studies in a college that is very far away from his father's house and when he eventually comes home for a short visit, feels repulsed by the presence of his stepmother: "it had upset me, throughout the day, to watch her handle the cutlery, the tea kettle, at one point to hold the telephone and speak with my father to learn that he was on his way home" (p. 279). He wishes that his father had removed all his mother's signs: "When my father had tried to remove the signs of my mother from the house I blamed him for being excessive, but now I blamed him for not having done enough" (p. 279). He tries to ignore his family as far as possible, excusing himself from every trip and entertainment: for Christmas, his father arranges for a family trip to Disney World, but Kaushik refuses to accompany them, making up something about there being a winter session at his college.

It is after catching his stepsisters one night uncovering his mother's photographs that Bhabha's unhomely moment eventually creeps on Kaushik. He gets into the car while having no idea where to go. He spends the first night in a motel by the road and resumes his wandering next day. He does the same things for days: "driving up the coast, eating in restaurants when I was hungry, finding motels when I was tired", until he reaches the border of Canada (p. 289). Kaushik observes that the desolation of the landscape draws him, "claim me as nothing had in a long time" (p. 290). He tells us that this is the first time he travels by himself and discovers that he likes it: "No one in the world knew where I was, no one had the ability to reach me. It was like being dead, my escape allowing me to taste that tremendous power my mother possessed forever" (p. 290). He then begins to go through his mother's photographs, but after looking at a few he finds himself unable to bear their sight; so he digs a hole into the ground and buries them.

Kaushik's obsession with photos and photography throughout the narrative seems to be an important indicator of this diasporic subject's unhomely nature. Drawing on such critics as John Berger and Jean Mohr (quoted in Banerjee 2010: 44) who have suggested that "a photograph arrests the flow of time in which the event photographed once existed" Banerjee (2010) argues that Lahiri uses "photography's multi-temporality in order to comment on the theme of diaspora that is so central to her wider corpus" (p. 44). She claims that Lahiri foregrounds the trope of photography because of its double-edge: its ability to 
capture a moment and saves it for future and, conversely, its connection with absence and death. In Kaushik's case, the desire to photograph, according to Banerjee, is a means by which he attempts to retrieve the past. Instead of providing him with roots and access to the past, photography ironically exacerbates his sense of loss (Banerjee 2010: 45-46).

"Year's End" closes with Kaushik's announcement that his father is selling their house; that he is moving to a new place in a less isolated suburb of Boston: "And without our having to say it, I knew we were both thankful to Chitra for chafing under whatever lingered of my mother's spirit in the place she had last called home and for forcing us to shut its doors" (p. 293). Yet Kaushik tells us that he will not be following his father to this new home, because he makes plan to travel across the world after graduation.

\section{Going Ashore}

Lahiri mentions in an interview that her works are influenced by Hawthorne's, particularly his Marble Faun: "I was doing a lot of rereading when I was working on those stories, and I read and reread all of the Hawthorne I had not read. [...] In fact the [...] last story in the book, "Going Ashore" is partly set in Rome [and] was inspired by my reading the Marble Faun" (Bilbro 2013: 386). She has already foregrounded Hawthorne's Scarlet Letter in the title and epigraph of her collection: "I felt that these words were so beautifully expressing everything I was trying to write about, everything I was trying to do as a writer from the very beginning from my very first book, and I suspect until the end of my writing life" (Bilbro 2013: 386). Nevertheless, the Hawthornian attitude towards the past and tradition is most evident in her last story. As Bilbro points out although the necessity of learning how to belong to conflicting traditions runs throughout Lahiri's works, it is developed fully in "Going Ashore" (p. 386). Hawthorne believes that "in order to flourish in unaccustomed earth, one must accept the historical limits on one's individual agency and self-reflectively translate between one's adopted and native traditions" (p. 383). Lahiri's female protagonist, Hema, as Bilbro also points out, seems to exemplify this Hawthornian attitude. In "Going Ashore", we learn that she has recently received her Ph.D. in the Latin language and is going on a trip to Rome: "Like Calcutta, which she'd visited throughout childhood, Rome was a city she knew on the one hand intimately and on the other hand not at all - a place that fully absorbed her and also kept her at bay" (Lahiri 2008: 299). She knows its ancient language, rulers and writers: "Since eighth grade, reading Latin had been an addiction, every line a puzzle to coax into meaning" (p. 299). Hema's inclination towards translating Roman language phrases is indicative of her willingness to make a meaningful connection between her Indian legacies and her present situation as a Western woman. Indeed, Hema, unlike Kaushik, seems to have opted for an in-between space.

On the other hand, Hawthorne, as quoted in Bilbro 2013: 383, also posits that "characters who attempt to stop outside of tradition and act as "ahistorical agents" inevitably doom themselves to futile, internal antagonism; they remain 
bound to a past they want to escape and unable to root themselves in any tradition". I will argue that it is this theme that Lahiri foregrounds in Kaushik's case. In the last story, we learn that Kaushik has been unable to root himself, either physically or emotionally. When we meet him in "Going Ashore", he is in Rome working on a photo essay. As the narrative flashes back, the narrator tells us that Kaushik's life as a photojournalist begins nearly twenty years ago, "wandering through Latin America in 1987, living off the money his father gave him after he graduated from college" (p. 303). He spends a few months in Mexico, then working his way through Guatemala, El Salvador, and then Buenos Aires. When he turns thirty he is hired by The New York Times, and they send him to Africa and then to the Middle East. The narrator observes that, thanks to his job, Kaushik could permanently avoid the United States: "occasional trips to New York to meet with an editor, to pick up equipment - this was the extent of his time in America, and there were trips when he'd not bothered to tell his father he was in the country" (p. 305). Moreover, Kaushik has also little to do with India: "He had not gone back since the year his mother died, had never gone there for work" (p. 310).

Finally, we learn that Kaushik has recently accepted a position as a photo editor for an international newsmagazine in Hong Kong. The magazine pays for his move but really apart from his car, the narrator observes, Kaushik owns little to bother him: "it was nothing like the times he moved with his parents in which all the furniture and paintings and tea sets were packed to follow them on cargo ships" (p. 309). Unlike his mother who cares so much about her house that "it didn't matter where she was in the world, or whether or not she was dying", the narrator tells us, "Kaushik never fully trusted the places he'd lived, never turned to them for refuge" (p. 309). From his childhood he has always preferred outdoors, to be "away from the private detritus of life" (p. 309). Surprisingly, his earliest memories of America were all outdoors: "A chain-link fence matted with forsythia. The herringbone pattern of bricks on a sidewalk" (p. 309). That is why he is drawn to photography in the first place because it gets him out of the house: "He wanted to believe that he was different, that in ten minutes he could be on his way to anywhere in the world" (p. 309).

As the narrative progresses, we also learn that Kaushik, at forty, has not yet formed a permanent emotional attachment. The narrator tells us that his only serious affair has been with an Italian woman, Franca; he meets her in a relief agency in Cameroon. The narrator observes that: "For years he had drifted across the globe without making meaningful ties" (p. 306). However, Kaushik suddenly finds himself sharing an apartment with Franca, driving out to an Italian restaurant to eat polenta and roasted rabbit at her grandmother's home. The affair, however, ends bitterly: neither can he come up with a reason to break up nor bring himself to propose. Kaushik convinces himself at the time that the problem is Franca's "inability to take hold of him", not the other way round: "and so he left the tears and fury in Milan and took the train down to Rome", and then flew to Buenos Aires (p. 307). Even when the Second "Intifada" draws Kaushik to the Middle East and he stays on in Europe, he never tells Franca that he is living in Italy, "never once running into her" (p. 307). 
As the focal point switches to Hema, we learn more about Kaushik's centrifugal living. The narrator tells us that Kaushik invites Hema to his apartment after he meets her at a party in Italy. There he tells her that he has recently been in Ramallah, covering Arafat's funeral. Hema notices that Kaushik watches an international news channel almost always. That "his work depended wholly on the present, and on things yet to come" (p. 315). She asks him once to show her his website. Hema sees lots of terrible images: "Buses blasted apart by bombs, bodies on stretchers, young boys throwing stones (p. 315). These pictures make Hema appreciate Kaushik's "ability, perhaps his need, to connect to strangers in this way, and the willingness of strangers to connect to him" (p. 316). She begins to understand his willingness and need to disappear at any moment. She notices that he lives in "a rented room with rented sheets and towels. In the corner his camera bags and tripods were always packed, his passport always in his pocket" (p. 316). Hema could also guess that Kaushik has been with many women, that she is no different: "From the very beginning she had felt cleareyed, aware that in a matter of weeks it would end" (p. 317). At the end of their trip, Kaushik asks Hema not to marry Navin but he does not ask her to marry him: "I'm not interested in any sort of arrangement", he tells her in a cold tone (p. 323). Even though Hema is the only person he has met so far in his adult life who has some understanding of his past, "the only woman he wanted to remain connected to", Kaushik cannot bring himself to propose to her; he simply asks her to come with him to Hong Kong, calling her a coward after she refuses his "selfish" and "unfair" request (p. 323).

At the end of the story, we find Kaushik in Thailand for a layover before starting his new job. The narrator tells us that he spends his days by the beach eating local dishes and taking photographs. It is on a boat trip that we suddenly lose sight of Kaushik. The narrative is resumed by Hema in India where she is getting married. She relates that a tsunami has recently hit southeast Asia, uprooting Kaushik forever.

\section{Conclusion}

Allusions dominate "Hema and Kaushik": references to the exile of the Jews in October 1943, Senegalese immigrants in Brescia, Honduran border refugee camp, Palestine-Israel conflict, American soldiers in Iraq, etc. However, this study does not propose that the text is politically involved. What it attempts to suggest is that Jhumpa Lahiri's allusions are also in line with her narrative, the narrative of unhomeliness. Including such references are all part and parcel of composing an acceptable literary text especially in the twenty-first century. This study tried to show that "Hema and Kaushik" is a narrative permeated by unhomeliness both in the form and the content. The narrative structure, the focal points, the narrative's movement across multiple geographical locations, the employment of flashbacks, and numerous historical and political allusions are all examined in this essay to prove this argument. 
This study devotes considerable attention and space to the male protagonist, Kaushik. It is argued that Kaushik represents a typical postmodern postcolonial subject whose disorientation comes from the destabilization of the centers that contain him. This study examines such centers as home/homeland, family, and affective ties in each story of the trilogy. Moreover, it tries to show how Lahiri foregrounds Hawthorne's notion of "ahistorical agency" in the last story of this trilogy, "Going Ashore". By choosing an unhappy ending for this protagonist, Lahiri artistically manages to convey the futility of Kaushik's struggle to free himself from the past. In his struggles along the two dimensions of place and time, as this study shows, Kaushik is suspended. He cannot get to the seashore. In his boat he is afloat, after being cast adrift by his experiences of unhomeliness. Indeed, Kaushik surmounts two conditions: no like for belongings and no sense of belonging; no connection to the past. However, he fails to build new connections and his musing and venturing anchor does not hold anywhere or in anytime, but rather remains detached in measureless oceans of space.

\section{References}

Alfonso-Forero AM (2011) Translating Postcolonial Pasts: Immigration and Identity in the Fiction of Bharati Mukherjee, Elizabeth Nunez, and JhumpaLahiri. Doctoral Thesis, University of Miami, USA.

Banerjee B (2010) Diaspora's Dark Room: Photography and the Vision of Loss in JhumpaLahiri's "Hema and Kaushik". Journal of Commonwealth Literature 45(3): 443-456.

Bhabha HK (1994) The Location of Culture. New York: Routledge.

Bilbro J (2013) Lahiri's Hawthornian Roots: Art and Tradition in Hema and Kaushik. Critique 54(Sept.): 380-394.

Fadda-Conrey C (2009) Transnational Diaspora and the Search for Home in Rabih Alameddine's I, the Divine: A Novel in First Chapters. In L Al Maleh (Eds.), Arab Voices in Diaspora. New York: Rodopi.

Habib MAR (2005) A History of Literary Criticism: From Plato to the Present. UK: Blackwell.

Huddart D (2006) Homi K. Bhabha. London: Routledge.

Lahiri J (1999) The Interpreter of Maladies. Boston: Houghton Mifflin.

Lahiri J (2008) Unaccustomed Earth. New York: Vintage Contemporaries.

Lahiri J (2013) The Lowland. New York: Alfred A. Knopf.

Moslund S (2010) Migration Literature and Hybridity. New York: Palgrave Macmillan.

Munos D (2013) After Melancholia: A Reappraisal of Second-Generation Diasporic Subjectivity in the Work of Jhumpa Lahiri. Amsterdam \& New York: Rodopi. 